\title{
Effects of food form and timing of ingestion on appetite and energy intake in lean and obese young adults
}

\author{
Mattes RD and Campbell WW \\ Purdue University, W. Lafayette, IN 47906
}

\section{Abstract}

Objective-Overweight and obesity have been attributed to increased eating frequency and the size of eating events. This study explored the influence of the timing of eating events and food form on appetite and daily energy intake.

Design-Cross-over, clinical intervention where participants consumed $300 \mathrm{kcal}$ loads of a solid (apple), semi-solid (apple sauce) and beverage (apple juice) at a meal or 2 hours later (snack).

Subjects-Twenty normal weight (body mass index - BMI $=22.6 \pm 1.8 \mathrm{~kg} / \mathrm{m}^{2}$ ) and 20 obese $\left(\mathrm{BMI}=32.3 \pm 1.5 \mathrm{~kg} / \mathrm{m}^{2}\right)$ adults. There were 10 males and 10 females within each BMI group.

Measurements-On 6 occasions, participants reported to the laboratory at their customary midday meal time. Appetite questionnaires and motor skills tests were completed upon arrival and at 30min intervals for the 2 hours participants were in the laboratory and at 30min intervals for 4 hours after leaving the laboratory. Diet recalls were collected the next day. Data were collected between January of 2006 and June of 2007.

Results-Whether consumed with a meal or alone as a snack, the beverage elicited the weakest appetitive response, the solid food form elicited the strongest appetitive response and the semi-solid response was intermediate. The appetite shift was greatest for the solid food when consumed as a snack. The interval between test food consumption and the first spontaneous eating event $>100 \mathrm{kcal}$ was shortest for the beverage. No significant treatment effects were observed for test day energy intake or between lean and obese individuals.

Conclusion-Based on the appetitive findings, consumption of an energy-yielding beverage either with a meal or as a snack poses a greater risk for promoting positive energy than macronutrientmatched semi-solid or solid foods consumed at these times.

\section{Keywords}

food form; beverage; appetite; food intake; meal timing; meal pattern

\section{Introduction}

Increased eating frequency $(1,2)$ and energy derived from beverages $(3-5)$ are trends implicated in the dietary contribution to overweight and obesity. Between 1977-8 and 1994-6 adult males

Address Correspondence to: Richard D. Mattes, MPH, Ph.D., R.D., Professor of Foods and Nutrition, Department of Foods and Nutrition, Purdue University, 212 Stone Hall, 700 W State Street, West Lafayette, IN 47907-2059 U.S.A., 765-494-0662 ph, 765-494-0674 fax, E-mail: mattes@purdue.edu.

Publisher's Disclaimer: This is a PDF file of an unedited manuscript that has been accepted for publication. As a service to our customers we are providing this early version of the manuscript. The manuscript will undergo copyediting, typesetting, and review of the resulting proof before it is published in its final citable form. Please note that during the production process errors may be discovered which could affect the content, and all legal disclaimers that apply to the journal pertain. 
and females increased the number of times they ate daily by $15 \%$ (from 3.9 to 4.5 times/d) (1) and doubled the consumption of sweetened beverages (from 70 to $141 \mathrm{kcal} / \mathrm{d}$ ) (3). Over this time period, most of the increased total energy intake $(268 \mathrm{kcal} / \mathrm{d}$ and $143 \mathrm{kcal} / \mathrm{d}$ in males and females, respectively) could be accounted for by the energy contributed by snacks (241 and $160 \mathrm{kcal} / \mathrm{d}$, respectively) (1). Approximately 95\% of Americans regularly consume soda (4) and it is the single largest source of energy in the population's diet (5). Sweetened beverages account for approximately $21 \%$ of daily energy intake in the United State's population (3).

The trends in eating frequency and beverage ingestion are not entirely independent. Sweetened beverages contributed disproportionately to the energy obtained through snacks $(11.6 \%)$ compared to meals $(6.1 \%)$ in the $1994-6$ period (6). Their contribution to daily snack energy increased by about $9.1 \%$ between $1977-78$ and 1994-96 and were roughly equal to desserts (15.6\% versus $15.7 \%)$ as the largest contributor of energy from snacks in 1994-6 (7).

Several factors might contribute to these trends. First, the incentive to consume sweetened beverages may have changed. There is an increasing array of readily accessible, palatable and inexpensive energy-yielding beverages, as well as increased consumption outside the house and societal acceptance of drinking in nearly all leisure time or work contexts (8-13).

Beverages containing stimulants and nutrients are also increasingly promoted to enhance health and performance (14-18). Additionally, the largest increase in snacking energy was derived from salty snacks (6) which could augment thirst (19).

Second, the low satiety value of beverages may lead to a weak compensatory dietary response (20). Thus, beverages add energy to eating events rather than substituting for other energy sources. This may be especially problematic for beverages consumed as snacks as they are least likely to moderate intake at subsequent eating events $(21,22)$. This issue is especially topical given legislation has been proposed or passed in many states limiting sweetened soft drink availability during school hours $(23,24)$. This may shift beverage consumption to after school (i.e., between meals) with unintended undesirable results. While ingestion of sweetened energy-yielding beverages as snacks may be especially problematic for energy balance, intake at meals may contribute additional energy. Approximately $75 \%$ of drinking is periprandial (25). The low satiation/satiety property of energy-yielding beverages also permits greater intake within (26) or at subsequent (27) meals when consumed at a meal.

There is accumulating evidence linking energy-yielding sweetened beverage consumption with positive energy balance, weight gain and body mass index (BMI) (28-30), and evidence suggesting that obese individuals have higher beverage intake $(31,32)$ and realize greater effects of moderating intake compared to lean individuals (33). Thus, the aim of this study was to assess the effects of food form (solid, semi-solid and beverage forms) and intake pattern (with a meal or as a snack) on appetite and energy intake in lean and obese individuals. It was hypothesized that sweetened beverage consumption, both with meals and as snacks, will have weaker effects on appetite and energy intake than semi-solid and solid forms of the food, especially among obese individuals.

\section{Methods}

\section{Participants}

Participants were initially recruited through public advertisements that directed them to an online screening questionnaire eliciting demographic, health, and dietary information. Once completed, this was reviewed by research staff for participant eligibility. The eligibility criteria included: males and females, $18-60$ years of age, BMI between 18 and $25 \mathrm{~kg} / \mathrm{m}^{2}$ or 30 and 35 $\mathrm{kg} / \mathrm{m}^{2}$, weight stable (no deviation greater than $5 \mathrm{~kg}$ over past 3 months), self-reported good health, not initiating or terminating the use of medications reported to affect appetite or body 
weight during the proposed study period, stable activity (no deviation >1X/wk @ $30 \mathrm{~min} /$ session), low dietary inhibition ( $<14$ on the Three Factor Eating Questionnaire (34)) and regular eating habits (i.e., $\geq 3$ meals per day, including breakfast). Anthropometric indices were confirmed during a baseline evaluation session when measurements were obtained for height (standing without shoes) (Model 602 Holtain Stadiometer, Seritex, Inc., Carlstadt, NJ) weight (in gown) (Model S100 scale, Scale-Tronix, Inc., Carol Stream, IL) and body composition (bioelectric impedance analysis (BIA) (Model TBF-410 Body Composition Analyzer, Tanita Corp. of America, Arlington Heights, IL) and air displacement plethysmography (Model 2000A Bod-Pod, Life Measurement, Inc., Concord, CA) by a researcher. Participants meeting eligibility criteria and choosing to participate signed an informed consent form. The protocol was approved by the University Institutional Review Board. All applicable institutional and governmental regulations concerning the ethical use of human volunteers were followed during this research.

\section{Protocol}

Testing-Participants consumed a morning meal, customary for them, and no other food or beverage for at least 3 hours before reporting to the testing facility to complete a diet recall for each of the six trial days. Upon arrival, a finger prick blood sample was collected to verify, based on their fasting glucose concentration, they had not eaten recently and a questionnaire eliciting information about their mood, appetite, strength, and fine motor skills was completed. To minimize the likelihood participants would alter their diet if they knew it was being monitored, they were informed that the intent of the study was to assess the effects of food on motor skills and coordination. So, they completed a variety of motor tasks (e.g., rotary tracking, hand steadiness, reaction time) and questionnaires of psychological state at 30 minute intervals while in the laboratory for 6 hours (data not reported). Data were collected between January, 2006 and March, 2007.

Six different treatments were administered. On three visits, participants were presented with a fixed portion midday meal providing $25 \%$ of their estimated daily energy requirement and a macronutrient distribution of 50\% carbohydrate, $35 \%$ fat, and $15 \%$ protein. The foods were peanut butter and jelly sandwich, baby carrots and whole milk. One-half of the energy was provided as beverages and one-half as solids. In addition, each participant was provided either a beverage (apple juice), semi-solid (apple sauce) or solid (apple) supplement containing an additional $10 \%$ of their estimated daily energy need. The beverages, semi-solid and solid were matched for macronutrient composition, but did differ in fiber and volume. Given the young age and mobility of participant's their estimated total energy requirement was set at 1.75 times resting energy expenditure estimated based on the Schofield equations (35).

On the other three visits, participants were presented the same fixed portion meal with the exception of the timing of ingestion of the fluid or solid supplement. For snack trials, the supplement was provided 2 hours after the meal in either fluid or solid form in randomized order. The participants were required to consume the supplement at the end of the 2-hour postmeal period, just prior to leaving the laboratory for the rest of the day. Participants returned to the laboratory the following day to complete a diet recall of all foods eaten after leaving the laboratory on the previous day.

Dietary Analyses-Participants kept diet records with instructions to include all foods consumed on each test day. This was only used to aid their memory when they were asked to recall all foods and beverages consumed on the following day during an in-person interview using the multipass Nutrition Data System (NDS) nutrition database (Version 5.0_35, 2006, Minneapolis, MN). Interviews were conducted by a single individual experienced with the system and method. However, analyses were reviewed by a Registered Dietitian. 
Appetite Assessment-Appetitive responses were recorded by participants on visual analog scales on personal data assistants (PDAs) before and after consuming the meal, every thirty minutes for the subsequent 2 hours they were in the laboratory and hourly for six hours after leaving the laboratory. Questions included "How hungry do you feel right now? How full are you right now? How strong is your desire to eat right now? How strong is your feeling of thirst right now? How strong is your desire to eat something salty right now? How strong is your desire to eat something sweet right now? How strong is your desire to eat something fatty right now?" The scales were anchored with "not at all .../very weak" and "as ... I've ever felt/ very strong". The validity of this approach has been established (36,37). Food sample palatability was rated on a visual analog scale with end anchors of "dislike extremely" and "like extremely" after sampling each item.

Statistical Analyses-Differences in baseline group characteristics were explored by ttests. Treatment effects were assessed by a mixed-model, repeated measures analysis of variance. Meal timing (meal, snack) and food form (solid, semi-solid, beverage) were treated as within subject factors because they were assessed multiple times in the same individuals while BMI was treated as a between subjects factor because responses were contrasted between the lean and obese participants. The criterion for statistical significance was $p<0.05$, two-tailed. Data are reported as mean \pm standard error (SE). No differences were observed between the lean and obese individuals so the data were pooled for all analyses.

\section{Results \\ Participants}

The final sample was comprised of 20 lean and 20 obese individuals with 10 males and 10 females in each of these groups. The mean age and BMI of the lean group was 21.6 \pm 2.1 years and $22.6 \pm 1.8 \mathrm{~kg} / \mathrm{m}^{2}$, respectively. The mean age and BMI values for the obese group were 25.6 \pm 5.9 years and $32.3 \pm 1.5 \mathrm{~kg} / \mathrm{m}^{2}$.

\section{Appetite}

The ingestion of isoenergetic loads of juice, sauce or whole fruit led to significantly different post-ingestive reductions of hunger when included in the meal $(\mathrm{p}=0.025)$ (Figure 1). Post-hoc tests indicated hunger was significantly lower 30 minutes following whole fruit ingestion compared to the juice and sauce. Hunger ratings were significantly lower for the whole fruit compared to juice from 60-180 minutes after the meal. Similarly, there was a significant treatment effect when the loads were consumed 2 hours after the meal $(\mathrm{p}<0.001)$. Post-hoc tests revealed the post-ingestive ratings were lowest for the whole fruit, intermediate for the sauce and higher for the juice 30 and 60 minutes after ingestion (times 150 and 180 minutes). Ninety minutes after ingestion, the hunger ratings (time 180 minutes) were significantly lower for the whole fruit treatment compared to juice and were lower for the sauce compared to juice 120 minutes later (time 240 minutes). There were no differences between lean and obese individuals for hunger ratings following ingestion of the juice, sauce or whole fruit with a meal or two hours later (data not shown).

The findings related to fullness were largely the reverse of those for hunger (Figure 2). The ingestion of isoenergetic loads of juice, sauce or whole fruit lead to significantly different postingestive fullness ratings when included in the meal $(\mathrm{p}=0.026)$. Post-hoc tests indicated fullness was significantly lower for the juice compared to the sauce or whole fruit 30 and 60 minutes following ingestion and the juice was also less than the whole fruit at 90 minutes and the sauce at 120 minutes. Load ingestion also led to differential effects on fullness when consumed 2 hours after the meal $(\mathrm{p}=0.020)$. Fullness rating were lower for the juice compared to the whole fruit an sauce 30, 60 and 120 after ingestion (times 150, 180 and 240 minutes) and lower than 
ratings after whole fruit only at 90 minutes. There were no differences between lean and obese individuals for hunger ratings following ingestion of the juice, sauce or whole fruit with a meal or two hours later.

The contribution of the apple load to the reduction of hunger when the apple was incorporated into a meal was significantly $(\mathrm{p}=0.028)$ smaller than the reduction of hunger that followed ingestion of the apple alone two hours after the meal (Figure 3). No significant differences were observed with the sauce or whole fruit. There were no differences between BMI groups.

Hunger ratings at the time of the first eating occasion after lunch and load ingestion were similar regardless of load form and timing of load ingestion (Figure 4). Mean premeal ratings for all conditions were similar, varying only from $40-46 \mathrm{~mm}$ on the $100 \mathrm{~mm}$ scale and the largest standard error was only $4.1 \mathrm{~mm}$. Significant correlations were observed between ratings after whole fruit and both juice $(\mathrm{r}=0.35, \mathrm{p}=0.038)$ and sauce $(\mathrm{r}=0.44, \mathrm{p}=0.008)$. None of the hunger ratings were significantly correlated with energy intake at that eating occasion.

Self-reported hand grip strength and steadiness were not differentially affected by ingestion of juice sauce or whole fruit with a meal or two hours later. These findings indicate the changes noted in appetitive sensations reflect true sensation differences rather than a bias in scaling.

\section{Intermeal interval}

The time interval between ingestion of the experimental lunch and the first self-initiated eating event where $\geq 100 \mathrm{kcal}$ were ingested was shorter when the load was a beverage than if the isoenergetic load of sauce or whole fruit was consumed (Figure 5). When the load was ingested with the meal, the intervals for the juice, sauce and whole fruit were $275 \pm 20,319 \pm 18$ and 312 \pm 19 minutes, respectively. The difference between the juice and sauce treatments was significant $(\mathrm{p}=0.011)$ and approached significance for the juice versus whole fruit comparison $(\mathrm{p}=0.085)$. When the loads were consumed 2 hours after the meal, the mean interval was 290 $\pm 18,325 \pm 19$ and $337 \pm 18$ minutes, respectively. The difference between the juice and whole fruit was significant $(\mathrm{p}=0.018)$ and the comparison between the juice and sauce approached significance $(\mathrm{p}=0.093)$. The time to first eating occasion did not differ with timing of load. There were no inter-meal interval differences between lean and obese individuals.

\section{Intake}

The form of the food load had no significant effect on energy intake at the first eating occasion of $>100 \mathrm{kcal}$ after ingestion of the experimental meal and the load whether consumed with the meal or two hours after (Figure 6). Similarly, there were no treatment effects on daily energy intake. There were no significant differences between the lean and obese participants for the first post-treatment meal or daily energy intake.

\section{Discussion}

There is considerable, long-standing evidence indicating food form acutely influences appetitive responses $(28,27)$. In accord with this literature, the present study revealed the beverage food form was associated with the weakest suppression of hunger and augmentation of fullness. The solid food form exerted the strongest effects and the semi-solid form was intermediate. However, the primary focus of this project was to determine whether consuming iso-energetic portions of the three food forms as a meal component leads to differential appetitive and dietary responses relative to consuming the items as a snack.

Fundamental to such test is a definition of snacks and meals. For the present purpose, the meal condition entailed consuming foods constituting $25 \%$ of each individuals estimated daily energy requirement at a time of day that coincided with a customary eating event labeled by 
the participant as a meal. The snack condition differed in that the load was consumed alone two hours after the experimental meal was consumed. Although there is evidence of a direct $(21,38,39)$, indirect $(40-43)$ or non-significant effect $(44,45)$ of eating frequency on energy intake, the literature on controlled tests of snacking, generally suggests such an eating event evokes little dietary compensation and promotes positive energy balance $(46,38,39)$. Further, it has been argued that energy-yielding beverage snacks should be especially problematic for maintaining energy balance (21). The present study found the timing of beverage energy intake did not alter mean daily hunger or fullness ratings. This also held for the semi-solid sauce, but the whole apple exerted a stronger appetitive effect when ingested as a snack. The basis of this differential response is not known, but physical property is a likely candidate. Solid foods may generally evoke stronger behavioral responses and may be more salient when consumed in isolation. There is evidence that texture is an important dimension of sensory specific satiety (47), solid foods are expected to be more satiating prior to ingestion (20) and solid foods are more common targets of food aversion learning (48).

Consistent with the weaker appetitive ratings with the beverage form, the interval between the experimental lunch and the next spontaneous eating occasion of $>100 \mathrm{kcal}$ was shortest with the beverage. However earlier meal initiation was not associated with a difference in energy intake either within the first post-load meal or over the day. The experimental design of this trial differed from many preload design studies in that the challenge meal was not presented at a fixed time after preload ingestion, rather it was eaten upon request. The latter better simulates the free-living condition. The present data suggest that individuals generally delayed the onset of the evening meal until they reach a relatively common level of hunger. The standard error of premeal ratings for all conditions was only $4.1 \mathrm{~mm}$. Given such a narrow range of values, it is not surprising that premeal appetitive ratings were not correlated with intake at that meal.

The intermeal interval also did not predict intake at the first spontaneous eating occurrence. The weakness of the pre-meal interval as a predictor of intake at the meal has been reported previously, albeit not uniformly (49) in animal studies (50) and work exploring such an association in time isolation trials $(51,52)$. The likely explanation is that when meals are selfinitiated, the nature of foods selected and portion sizes tend to conform to customary practices. If true, this raises questions about extrapolating findings from trials where challenge meals are presented earlier than individuals would chose to eat. In this trial the intermeal interval was about 270-335 min, far longer than the customary 5-120 min intervals allowed in most preload trials.

Providing the different food forms with meals or as snacks did not alter intake of the subsequent meal or over total day. Several mechanisms may account for this observation. One holds that the impact of snack ingestion on appetitive sensations is transient so if consumed well before a meal, its effect will be dissipated $(21,38)$. Another possibility is that effects are not observed without expectations of a load's post-ingestive effects acquired through associative learning (46). While all foods were familiar to participants, the novelty of the testing environment may have disrupted "normal" behavior.

This study also permitted a comparison of responses between lean and obese individuals. To the extent that differential appetitive and compensatory dietary responses contribute to individual variability in BMI, it was hypothesized that the obese participants would have lesser reductions of appetite and intake compared to the lean participants after ingesting the experimental loads, especially the beverage. Obese individuals reportedly have higher beverage consumption (32). This suggests they either experience weaker appetitive signals from energy-yielding beverages or are less responsive to those signals. Supporting the latter view, there are data indicating satiety hormone responses (e.g., insulin (53); glucose-like 
peptide (GLP-1) (54)) of obese individuals are greater than those of their lean counterparts. Further, gastrointestinal dynamics (e.g., gastrointestinal (GI) transit, gastric acid secretion, pancreatic exocrine response to a fluid meal are greater in obese compared to lean individuals) (55). Nevertheless, the present study revealed no significant differences between the lean and obese participants. This may be attributed to a true lack of difference or methodological issues. Blunted satiety has been reported in obese individuals, but factors influencing appetitive sensations, unrelated to BMI, such as resting gastric volume, also contribute (56). Their modulation would diminish contrasts between lean obese individuals. Characteristics of the study population could also account for the lack of difference. Eligibility criteria included weight stability and a regular three "meal" per day eating pattern. While the obese participants had higher BMI's, if they were truly weight stable, their regulatory precision would have been comparable to the lean participants during the assessment period. Assessing individuals during periods of energy imbalance may be more revealing. There is also a substantial literature linking meal skipping with higher energy intake and BMI $(57,58)$. The direction of causality is an issue with such studies, but excluding individuals with less regular eating patterns may also have compromised the present study's ability to identify lean versus obese group differences.

There are several limitations of this study that necessitate careful interpretation of the findings. First, this was an acute feeding trial so it precluded the opportunity to assess longer-term dietary responses that could moderate energy balance and body weight. Second, to reduce response variance and aid identification of treatment effects, a highly selective sample was recruited (i.e., weight stability, regular eating pattern). Further, a portion of the testing was conducted in a laboratory setting that permitted tight experimental control, but probably at the expense of some external validity. These latter two points may account for the weak association noted between appetitive sensations and intake.

\section{Conclusion}

The findings suggest beverages consumed alone as an afternoon snack or when incorporated into a midday meal lead to comparable, weak appetitive effects. Stronger effects were noted with a solid form of the same food and intermediate effects were observed with a semi-solid form. This would suggest that energy-yielding beverage consumption poses a particular risk for promoting positive energy balance when consumed either as a snack or with a meal. However, these appetitive effects did not translate into differences in energy intake. In the context of the greater literature documenting weak compensatory dietary responses to beverages $(27,28)$, it may be these findings are attributable to methodological constraints such as those noted above. There is a need to explore this issue among individuals with lifestyles and characteristics more likely to reveal differences before drawing conclusions about its nutritional importance. Further, the present observations raise questions about the nutritional relevance of acute feeding trials. In this study, spontaneous meal decisions did not occur until a common level of hunger was experienced and this occurred more than 2.5 hours after a load contributing only $10 \%$ of estimated energy need. Thus, presenting individuals with meal challenges in shorter intervals or when hunger is not in a relevant range (i.e., its low), can yield findings of uncertain applicability to customary eating patterns.

\section{Supplementary Material}

Refer to Web version on PubMed Central for supplementary material.

\section{References}

1. Cutler D, Glaeser E, Shapiro J. Why have Americans become more obese? J Econ Perspect 2003;17:93118. 
2. Jahns L, Siega-Riz AM, Popkin BM. The increasing prevalence of snacking among US children from 1977 to 1996. J Pediatr 2001;138:493-498. [PubMed: 11295711]

3. Nielsen SJ, Popkin BM. Changes of beverage intake between 1977 and 2001. Am J Prev Med 2004;27:205-210. [PubMed: 15450632]

4. Sfiligoj E. Beverage Market Index 1998. Beverage World 1998;117:52-60.

5. Block G. Foods contributing to energy intake in the US: data from NHANES III and NHANES 19992000. J Food Compos Anal 2004;17:439-447.

6. Nielsen SJ, Siega-Riz AM, Popkin BM. Trends in energy intake in U.S. between 1977 and 1996: Similar shifts seen across age groups. Obes Res 2002;10:370-378. [PubMed: 12006636]

7. Zizza C, Siega-Riz AM, Popkin BM. Significant increase in young adults' snacking between 19771978 and 1994-1996 represents a cause for concern! Prev Med 2001;32:303-310. [PubMed: 11304090]

8. Grimm GC, Harnack L, Story M. Factors associated with soft drink consumption in school aged children. J Am Diet Assoc 2004;104:1244-1249. [PubMed: 15281041]

9. Hendel-Patterson M, French SA, Story M. Parental attitudes towards soft drink vending machines in high schools. J Am Diet Assoc 2004;104:1597-1600. [PubMed: 15389421]

10. French SA, Lin BH, Guthrie JF. National trends in soft drink consumption among children and adolescents age 6 to 17 years: Prevalence, amounts, and sources, 1977/1978 to 1994/1998. J Am Diet Assoc 2003;103(10):1326-31. [PubMed: 14520252]

11. Duffey KJ, Popkin BM. Adults with healthier dietary patterns have healthier beverage patterns. J Nutr 2006:2901-2907. [PubMed: 17056820]

12. Wiecha JL, Finkelstein D, Troped PJ, Fragala M, Peterson KE. School vending machine use and fastfood restaurant use are associated with sugar-sweetened beverage intake in youth. J Am Diet Assoc 2006;106:1624-1630. [PubMed: 17000195]

13. Storey ML, Forshee RA, Anderson PA. Beverage consumption in the US population. J Am Diet Assoc 2006;106:1992-2000. [PubMed: 17126630]

14. Sloan AE. Sea change in the beverage business. Food Technol 2003;57:20.

15. Roberts WA. Beverages with a boost. Prepared Food 2004;6:11-18.

16. Sloan AE. (a) Top 10 food trends. Food Technol 2007;61:23-39.

17. Sloan AE. (b) Market trends: The experts speak out. Food Technol 2007;61:59-65.

18. Lal GG. Getting specific with functional bevereages. Food Technol 2007;61:25-31.

19. He FJ, Marrero NM, MacGregor GA. Salt intake is related to soft drink consumption in children and adolescents: A link to Obesity? Hypertension 2008;51:629-634. [PubMed: 18287345]

20. DiMeglio DP, Mattes RD. Liquid versus solid carbohydrate: effects on food intake and body weight. Int J Obes Relat Metab Disord 2000;24:794-800. [PubMed: 10878689]

21. Booth DA. Mechanisms from models - Actual effects from real life: The zero-calorie drink break option. Appetite 1988;11:94-102. [PubMed: 3056269]

22. Dubois L, Farmer A, Girard M, Peterson K. Regular sugar-sweetened beverage consumption between meals increases risk of overweight among preschool-aged children. J Am Diet Assoc 2007;107:924934. [PubMed: 17524711]

23. Johnston LD, Delva J, O'Malley PM. Soft drink availability, contracts, and revenues in American secondary schools. Am J Prev Med 2007;33:S209-S225. [PubMed: 17884569]

24. National Conference of State Legislators. [accessed on 1/11/08]. http://www.ncsl.org/programs/health/ChildhoodObesity-2005.htm

25. McKiernan, F.; Hollis, JH.; McCabe, G.; Mattes, RD. The Relationship between Thirst, Hunger, Eating and Drinking in Adults. 10th Asian Congress of Nutrition; September, 2007; Taipei, Tiwan.

26. DellaValle DM, Roe LS, Rolls BJ. Does the consumption of caloric and non-caloric beverages with a meal affect energy intake? Appetite 2005;44:187-193. [PubMed: 15808893]

27. Mourao DM, Bressen J, Campbell WW, Mattes RD. Effects of food form on appetite and energy intake in lean and obese young adults. Intl J Obes. 2007(electronic publication)

28. Mattes RD. Beverages and positive energy balance: The menace is the medium. Intl J Obes 2006;30:S60-S65. 
29. Malik VS, Schulze MB, Hu FB. Intake of sugar-sweetened beverages and weight gain: a systematic review. Am J Clin Nutr 2006;84:274-88. [PubMed: 16895873]

30. Vartanian LR, Schwartz MB, Brownell KD. Effects of soft drink consumption on nutrition and health: a systematic review and meta-analysis. Am J Public Health 2007;97:667-675. [PubMed: 17329656]

31. Liebman M, Pelican S, Moore SA, Holmes B, Wardlaw MK, Melcher LM, Liddil AC, Paul LC, Dunnagan T, Haynes GW. Dietary intake behavior, and physical activity-related determinants of high body mass index in rural communities in Wyoming, Montana, and Idaho. Intl J Obes 2003;27:684692.

32. Gillis LJ, Bar-Or O. Food away from home, sugar-sweetened drink consumption and juvenile obesity. J Am Col Nutr 2003;22:539-545.

33. Ebbeling CB, Feldman HA, Osganian SK, Chomitz VR, Ellenbogen SJ, Ludwig DS. Effects of decreasing sugar-sweetened beverage consumption on body weight in adolescents: a randomized, controlled pilot study. Pediatrics 2006;117(3):673-80. [PubMed: 16510646]

34. Stunkard AJ, Messick S. The three-factor eating questionnaire to measure dietary restraint, disinhibition and hunger. J Psychosom Res 1985;29:71-83. [PubMed: 3981480]

35. Schofield WN. Predicting basal metabolic rate, new standards and review of the previous work. Hum Nutr Clin Nutr 1985;39C(Suppl 1):5-41. [PubMed: 4044297]

36. Flint A, Raben A, Blundell JE, Astrup A. Reproducibility, power and validity of visual analogue scares in assessment of appetite sensations in single test meal studies. Int J Obesity 2000;24(1):3848.

37. Jamison RN, Gracely RH, Raymond SA, Levine JG, Marino B, Herrmann TJ, Daly M, Fram D, Katz. Comparative study of electronic vs. paper VAS ratings: a randomized, crossover trial using healthy volunteers. Pain 2002;99:341-347. [PubMed: 12237213]

38. Porrini M, Santangelo A, Crovetti R, Riso R, Testolin G, Blundell JE. Weight, protein, fat, and timing of preloads affect food intake. Physiol Behav 1997;62:563-570. [PubMed: 9272665]

39. Marmonier C, Chapelot D, Louis-Sylvestre J. Metabolic and behavioral consequences of a snack consumed in a satiety state. Am J Clin Nutr 1999;70:854-866. [PubMed: 10539746]

40. Drummond SE, Crombie NE, Cursiter MC, Kirk TR. Evidence that eating frequently is inversely related to body weight status in male, but not female, non-obese adults reporting valid dietary intakes. Int J Obesity 1998;22:105-112.

41. Hampl JS, Heaton CLB, Taylor CA. Snacking patterns influence energy and nutrient intakes but not body mass index. J Hum Nutr Diet 2003;16(1):3-11. [PubMed: 12581404]

42. Ma Y, Bertone ER, Stanek EJ, Reed GW, Herbert JR, Cohen NL, Merriam PA, Ockene IS. Association between eating patterns and obesity in a free-living US adult population. Am J Epidemiol 2003;158 (1):85-92. [PubMed: 12835290]

43. Yungsheng M, Bertone ER, Stanek EJ, Reed GW, Herbert JR, Cohen NL, Merriam PA, Ockene IS. Association between eating patterns and obesity in a free-living US adult population. Am J Epidemiol 2003;158(1):85-92. [PubMed: 12835290]

44. Dreon D, Frey-Hewitt B, Ellsworth N, Williams P, Terry R, Wood P. Dietary fat: carbohydrate ratio and obesity in middle-aged men. Am J Clin Nutr 1988;47:995-1000. [PubMed: 3376914]

45. Edelstein S, Barrett-Connor E, Wingard D, Cohn B. Increased meal frequency associated with decreased cholesterol concentrations; Rancho Bernardo, CA, 1984-1987. Am J Clin Nutr 1992;55:664-669. [PubMed: 1550041]

46. Louis-Sylvestre J, Tournier A, Verger P, Chabert M, Delorme B, Hossenlopp J. Learned caloric adjustment of human intake. Appetite 1989;12:95-103. [PubMed: 2764558]

47. Sorensen LB, Moller P, Flint A, Martens M, Raben A. Effect of sensory perception of foods on appetite and food intake: a review of studies on humans. Int J Obesity 2003;27:1152-1166.

48. Mattes RD. Learned food aversions: A family study. Physiol Behav 1991;50:499-504. [PubMed: 1801001]

49. De Castro JM. Physiological, environmental, and subjective determinants of food intake in humans: a meal pattern analysis. Physiol Behav 1988;44:651-659. [PubMed: 3237851]

50. Collier G, Johnson DF, Mitchell C. The relation between meal size and the time between meals: Effects of cage complexity and food cost. Physiol Behav 1999;67:339-346. [PubMed: 10497950] 
51. Bernstein IL. Meal patterns in "free-running" humans. Physiol Behav 1981;27:621-623. [PubMed: 7323164]

52. Marmonier C, Chapelot D, Louis-Sylvestre J. Effects of macronutrient content and energy density of snacks consumed in a satiety state on the onset of the next meal. Appetite 2000;34:161-168. [PubMed: 10744905]

53. Teff K. Nutritional implications of the cephalic phase reflexes: Endocrine responses. Appetite 2000;34:206-213. [PubMed: 10744911]

54. Bowen J, Noakes M, Clifton PM. Appetite regulatory hormone responses to various dietary proteins differ by body mass index status despite similar reductions in ad libitum energy intake. J Clin Endocrinol Metab 2006;91:2913-2919. [PubMed: 16735482]

55. Wisen O, Johansson C. Gastrointestinal function in obesity: motility, secretion, and absorption following a liquid test meal. Metabolism 1992;41:390-5. [PubMed: 1372949]

56. Delgado-Aros S, Cremonini F, Castillo JE, Chial HF, Burton DD, Ferber I, Camilleri M. Independent influences of body mass and gastric volumes on satiation in humans. Gastroenterology 2004;126:432-440. [PubMed: 14762780]

57. Dwyer JT, Evans M, Stone EJ, Feldman HA, Lytle L, Hoewlscher D, Johnson C, Zive M, Yang M. Adolescents' eating patterns influence their nutrient intakes. J Am Diet Assoc 2001;101:798-802. [PubMed: 11478479]

58. Ma Y, Bertone ER, Stanek E, Reed GW, Hebert JR, Cohen NL, Merriam PA, Ockene IS. Association between eating patterns and obesity in a free-living US adult population. Am J Epidemiol 2003;158:85-92. [PubMed: 12835290] 


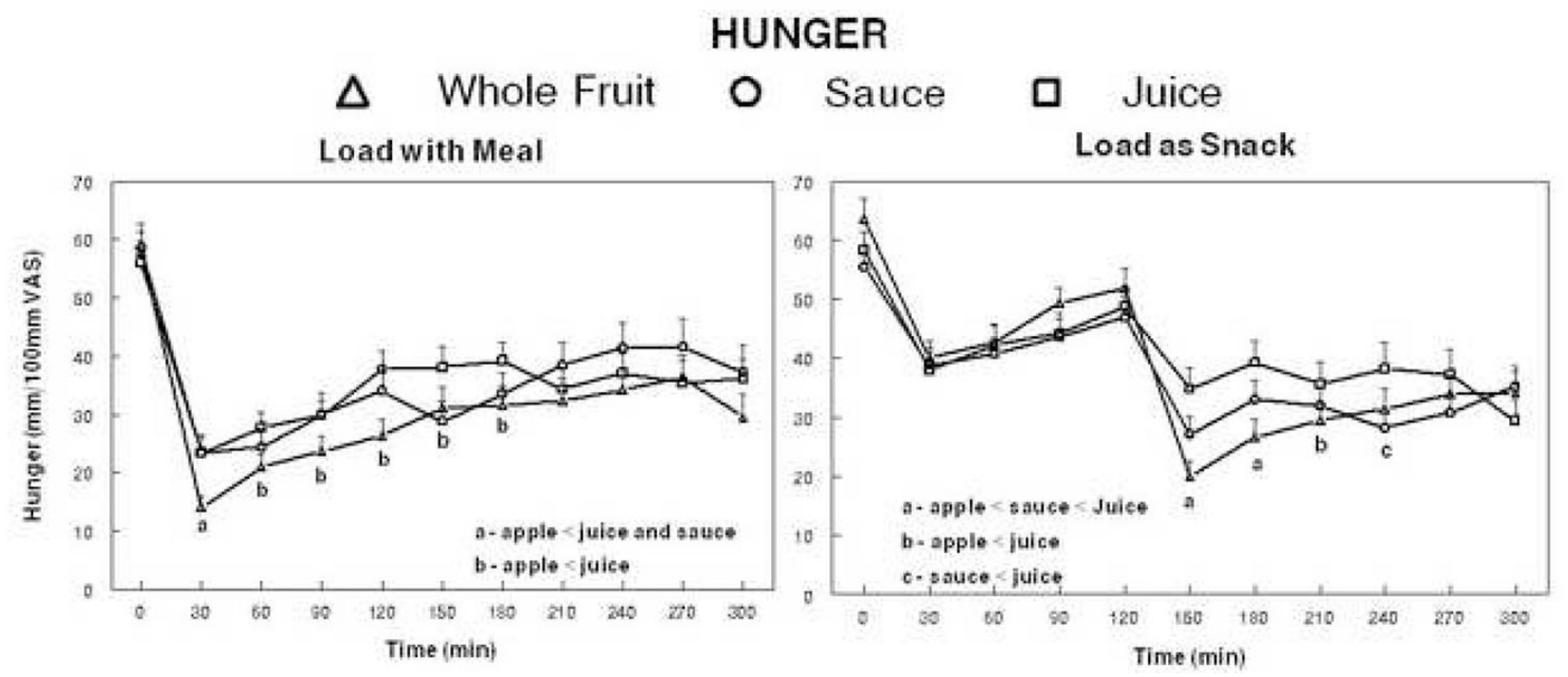

Figure 1.

Mean hunger ratings of 40 adults following ingestion of a meal providing $25 \%$ of each individual's estimated energy requirement (EER) with loads of juice, sauce or whole fruit providing an additional 10\% of each individual's (EER) (left panel) or with the same loads provided 2 hours after the meal (right panel). 


\section{FULLNESS}
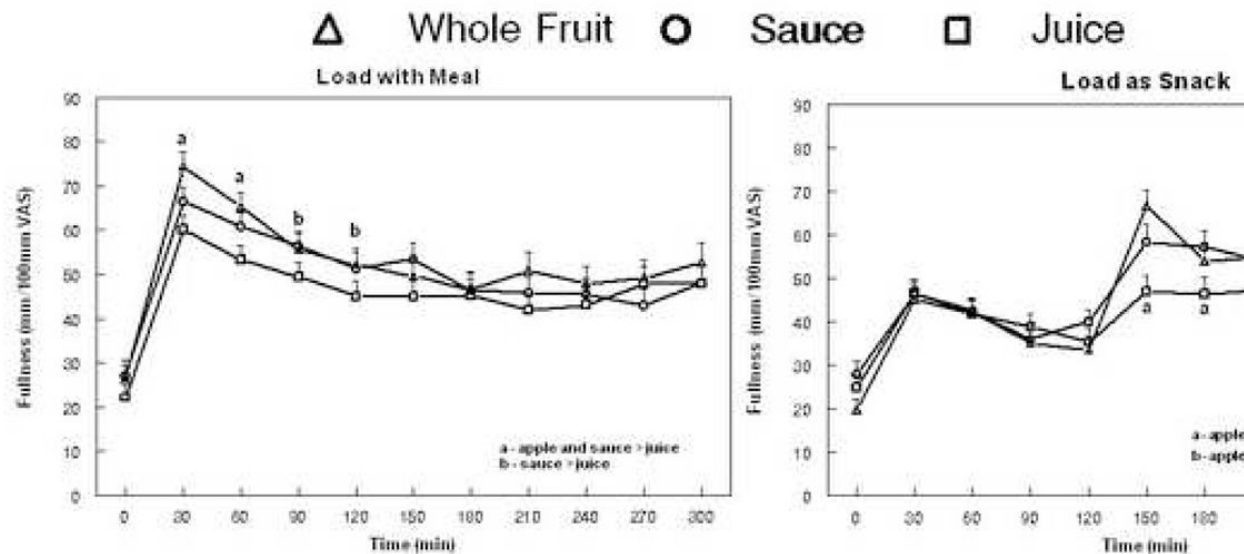

Figure 2.

Mean fullness ratings of 40 adults following ingestion of a meal providing $25 \%$ of each individual's estimated energy requirement (EER) with loads of juice, sauce or whole fruit providing an additional 10\% of each individual's (EER) (left panel) or with the same loads provided 2 hours after the meal (right panel). 


\section{APPETITE CHANGE}

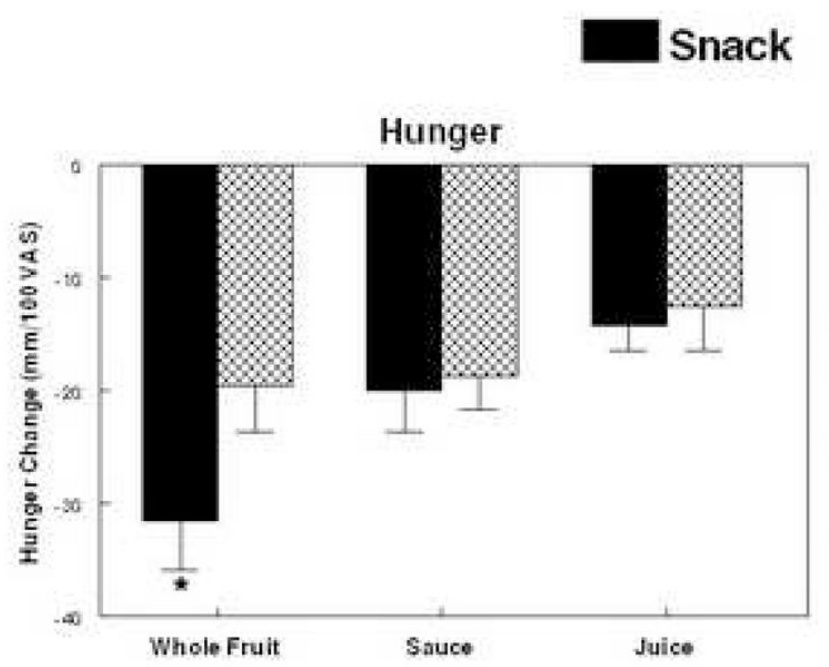

\section{Meal}

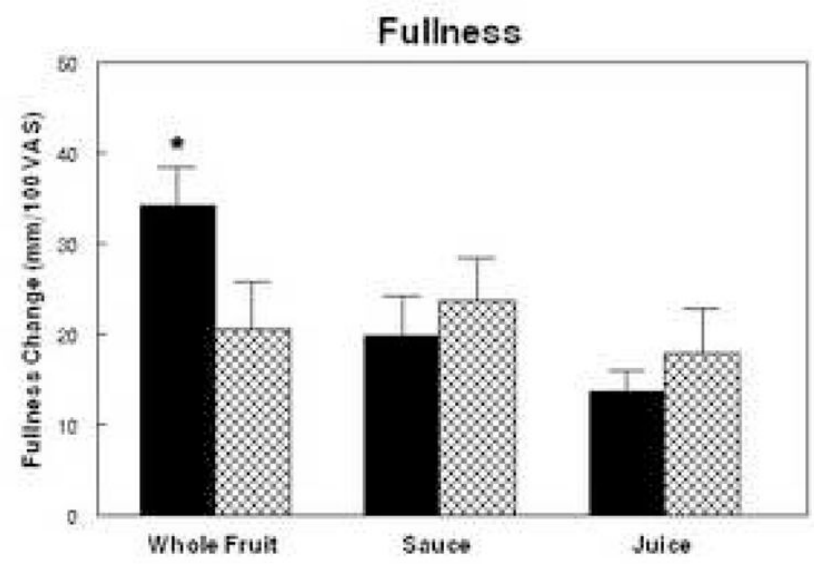

Figure 3.

Mean change of hunger and fullness following ingestion of a meal providing $25 \%$ of each individual's estimated energy requirement (EER) with loads of juice, sauce or whole fruit providing an additional 10\% of each individual's (EER) or with the same loads provided 2 hours after the meal. 


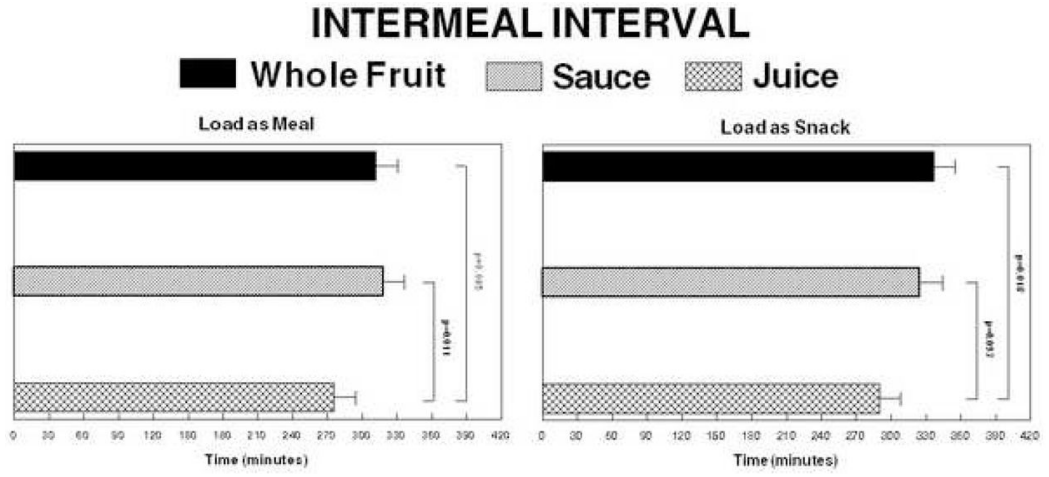

Figure 4.

Mean hunger ratings of 40 adults immediately prior to the ingestion of the first eating episode comprised of $\geq 100 \mathrm{kcal}$ following ingestion of a meal providing $25 \%$ of each individual's estimate energy requirement (EER) and a load contributing $10 \%$ of each individual's EER either with the meal (left panel) or 2 hours after the meal (right panel). Correlation coefficients in each bar represent the correlations between the hunger rating and energy consumed in that eating event. 
Energy of First

Post-Load Meal
Daily Energy

- First Post-Load Meal

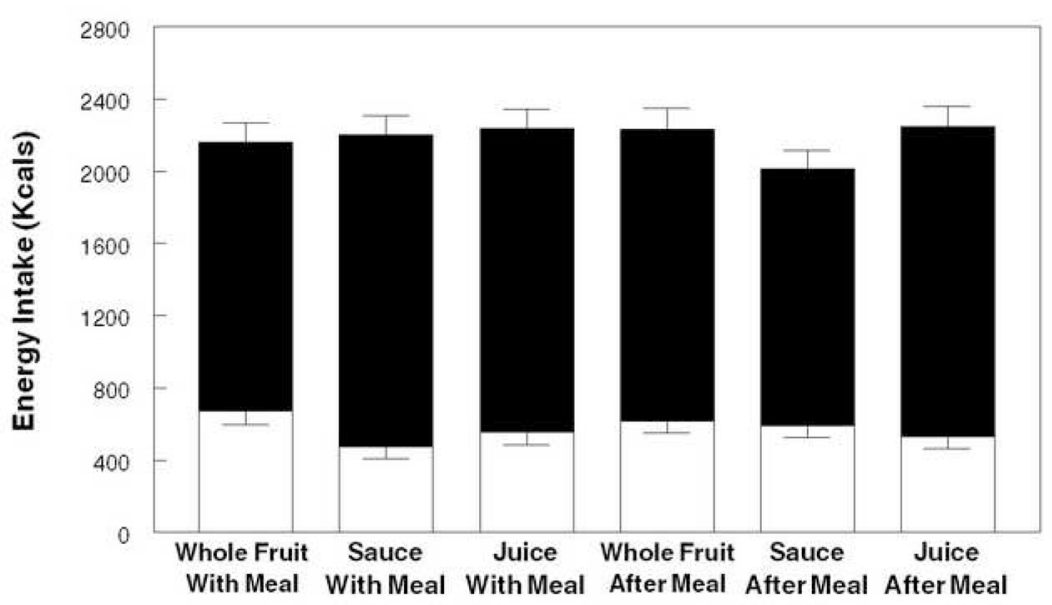

Figure 5.

Mean intervals between the end of the experimental lunch and the first spontaneous eating episode $\geq 100 \mathrm{kcal}$. The left panel depicts the intervals where the whole fruit, sauce and juice loads were consumed with the meal and the right panel depicts the intervals where the loads were ingested 2 hours after the meal. 


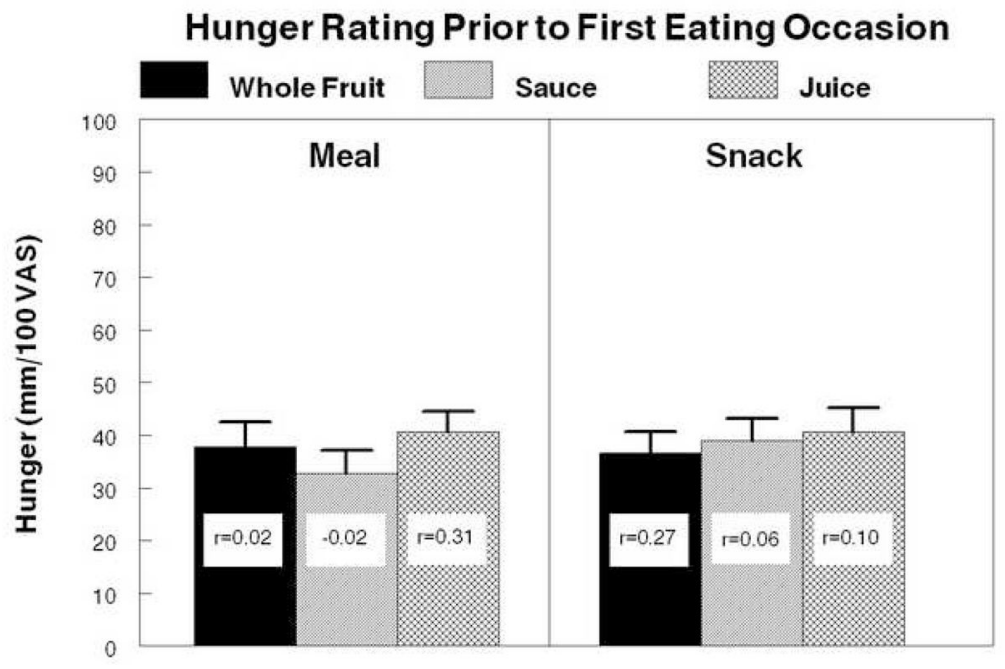

Figure 6.

Mean daily energy intake when ingesting whole fruit, sauce and juice loads providing $10 \%$ of estimated energy requirement (EER) a with a meal providing $25 \%$ of each individual's EER or 2 hours after the meal. The open portion of the bar depicts the energy ingested at the first eating episode comprised of $\geq 100 \mathrm{kcal}$ following ingestion of the meal and load under both time conditions. 